\title{
Vitamin D-Mentia: Randomized Clinical Trials Should Be the Next Step
}

\author{
Cédric Annweiler Olivier Beauchet
}

Department of Internal Medicine and Geriatrics, Angers University Hospital; Angers University Memory Center;

UPRES EA 2646, University of Angers, UNAM, Angers, France

\section{Key Words}

Vitamin D intake $\cdot$ Neurosteroid hormone $\cdot$ Trials .

Cognition $\cdot$ Alzheimer's disease $\cdot$ Older adults

\begin{abstract}
Hypovitaminosis $D$ is highly prevalent in the elderly. Its possible role in the pathogenesis of Alzheimer's disease (AD) is particularly important, as AD remains a public health concern with no current efficient treatment. Vitamin $D$ administration could be a multitarget stabilizing treatment for $A D$ since vitamin $D$ simultaneously targets several factors leading to neurodegeneration through immunoregulatory, antioxidant and anti-ischemic actions, as well as the regulation of neurotrophic factors, acetylcholine neurotransmitter and clearance of amyloid beta peptide, and the avoidance of hyperparathyroidism. By preventing neuronal loss, the question is whether correcting hypovitaminosis $D$ among older adults could also prevent AD-related cognitive decline. The cross-sectional associations between the vitamin $D$ intakes - whether from diet, sun exposure or drug supplements - and cognition strengthened this hypothesis, but prevented the finding of a cause and effect link. Pre-post studies showed an improvement of cognition concomitant with the increase in 25-hydroxyvitamin D concentrations. One randomized trial found that supraphysiological doses of vitamin $\mathrm{D}$ were not better than physiological doses at im-
\end{abstract}

\section{KARGER}

Fax +41613061234 E-Mail karger@karger.ch www.karger.com
(C) 2011 S. Karger AG, Basel

0251-5350/11/0374-0249\$38.00/0

Accessible online at:

www.karger.com/ned proving cognition in $\mathrm{AD}$. At this stage, only clinical trials testing vitamin $D$ supplements versus placebo can further determine the impact of vitamin $D$ administration on cognition and $A D$ with higher levels of evidence.

Copyright $\odot 2011$ S. Karger AG, Basel

\section{Introduction}

Alongside its long-known effects on phosphocalcic metabolism and bone, vitamin $\mathrm{D}$ exhibits neurosteroid properties indispensable to physiological functioning and protection of the central nervous system (CNS) [1-3]. Around one billion people are currently insufficient in vitamin D worldwide [4]. Most of them are older adults, with a prevalence ranging from 50 to $80 \%$ [4]. Since both hypovitaminosis $\mathrm{D}$ and cognitive decline/dementia are common in older adults, the involvement of age-related hypovitaminosis $\mathrm{D}$ in 'D-mentia' has recently been questioned [5].

\section{Vitamin D Status and Cognition}

The specific association of serum vitamin D status with cognition has been questioned repeatedly in recent years $[6,7]$ until the publication of a systematic review in 
2009, which provided elements of response [8]. More precisely, the authors underlined an association between hypovitaminosis $\mathrm{D}$ and global cognitive impairment measured with composite scores among older adults. They subsequently confirmed this association in a populationbased sample consisting of more than 750 communitydwelling women aged 75 and older [9]. In this cross-sectional study, vitamin D deficiency $<10 \mathrm{ng} / \mathrm{ml}$ doubled the risk of presenting with cognitive impairment measured with Pfeiffer's Short Portable Mental State Questionnaire (SPMSQ; odds ratio, OR $=2.03 ; 95 \%$ confidence interval $(C I)=1.17-3.53, p=0.01)$. Similarly, in the same year, two works reported higher risks of global cognitive decline in older adults with hypovitaminosis D compared to those with normal 25-hydroxyvitamin D (25OHD) status. First, Slinin et al. [10] highlighted an independent association between lower 25OHD levels and odds of cognitive decline by Modified Mini-Mental State Examination (3MS) performance among 1,138 men aged $\geq 65$ years and followed for 4.6 years on average ( $\mathrm{p}=0.04$ after adjustment for age, center and season tested). Second, Llewellyn et al. [11] showed a 1.60 -fold risk of losing at least 3 points on Mini-Mental State Examination (MMSE) in 6 years among 175 older adults with baseline 25OHD $<10 \mathrm{ng} / \mathrm{ml}$ (mean, 77.5 years; $80.0 \%$ women) compared to 157 subjects with $25 \mathrm{OHD} \geq 30 \mathrm{ng} / \mathrm{ml}$ (mean, 71.6 years; $39.5 \%$ women). Compared to previous cross-sectional studies, these longitudinal works established the temporal sequence of events and determined that low baseline vitamin $\mathrm{D}$ status may predict incident cognitive decline in the elderly.

Particularly, in the case of severe chronic hypovitaminosis $\mathrm{D}$, the lack of vitamin $\mathrm{D}$ appears to be associated with dementia-level cognitive impairment [12], with a 2.4-fold risk for moderately severe to severe all-cause dementia $(95 \% \mathrm{CI}=1.1-5.1, \mathrm{p}=0.02)$ in case of serum $25 \mathrm{OHD}<10 \mathrm{ng} / \mathrm{ml}$ compared to normal vitamin D status (mean, $86.0 \pm 0.4$ years; $66.1 \%$ women). More precisely, hypovitaminosis $\mathrm{D}$ may contribute to Alzheimer's disease $(\mathrm{AD})$ since lower $25 \mathrm{OHD}$ concentrations were found among $\mathrm{AD}$ patients compared to controls $[13,14]$ and since an association of vitamin D insufficiency $\leq 20 \mathrm{ng} /$ $\mathrm{ml}$ with the diagnosis of $\mathrm{AD}(\mathrm{OR}=2.51,95 \% \mathrm{CI}=1.04-$ $6.09, \mathrm{p}=0.04)$ was recently described among 318 older community-dwellers (mean, $73.5 \pm 8.1$ years; $72.6 \%$ women) [15].

Most recent works showed that the association between hypovitaminosis $\mathrm{D}$ and $\mathrm{AD}$ could be specifically explained by the occurrence of episodic memory disorders as well as executive dysfunction in the case of hypo- vitaminosis $\mathrm{D}$. Indeed, both hypovitaminosis $\mathrm{D}$ and $\mathrm{AD}$ are characterized by these specific cognitive disorders. First, episodic memory is impaired among AD patients, but has also been associated with hypovitaminosis D [16]. Second, impaired executive functions are usually described in AD [17]. Executive functions refer to the heterogeneous set of high-level functions (i.e., mental shifting, cognitive inhibition and information updating) required for flexible and appropriate behavior [18]. Interestingly, impairment of executive functions - and more particularly of mental shifting assessed with Trail Making Test part B - has been associated with hypovitaminosis D among community-dwelling older adults in crosssectional studies [19] as well as in longitudinal studies [11], with deleterious effects on information processing speed [19]. The involvement of hypovitaminosis D in ADrelated cognitive decline could be of particular importance since $\mathrm{AD}$ remains a public health concern with no current efficient treatment.

\section{AD: Underlying Mechanisms and Treatments}

$\mathrm{AD}$ is the leading cause of dementia, loss of autonomy and independency in the elderly. This public health problem will grow in coming decades. In order to delay this period for as long as possible and thus reduce its impact at an individual level and in terms of health costs, the development of efficient therapeutic strategies proves necessary.

\section{Underlying Mechanisms}

Although the pathophysiological bases of $\mathrm{AD}$ remain not fully understood, three main neurodegenerative mechanisms are likely to explain AD (fig. 1):

(1) Senile plaques (or amyloid plaques), corresponding to the extracellular aggregation of amyloid beta 42 (A $\beta 42)$ peptide [20]. They create inflammatory and oxidant stress resulting in the death of the affected neurons. In addition, they overactivate the MAP kinase responsible for controlling the phosphorylation of Tau proteins.

(2) Neurofibrillary degeneration, due to the increase in the phosphorylation of Tau disassembling from microtubules and aggregating in neurofibrillary tangles [20]. The consequence is neuron degeneration.

(3) Glutamatergic neuronal excitotoxicity, likely due to the preferential localization of amyloid beta peptides and phosphorylated Tau in glutamatergic synaptosomes [21, 22], leads to excessive calcium entry into the postsynaptic neuron, ending in neuronal necrosis and apoptosis $[23,24]$. 


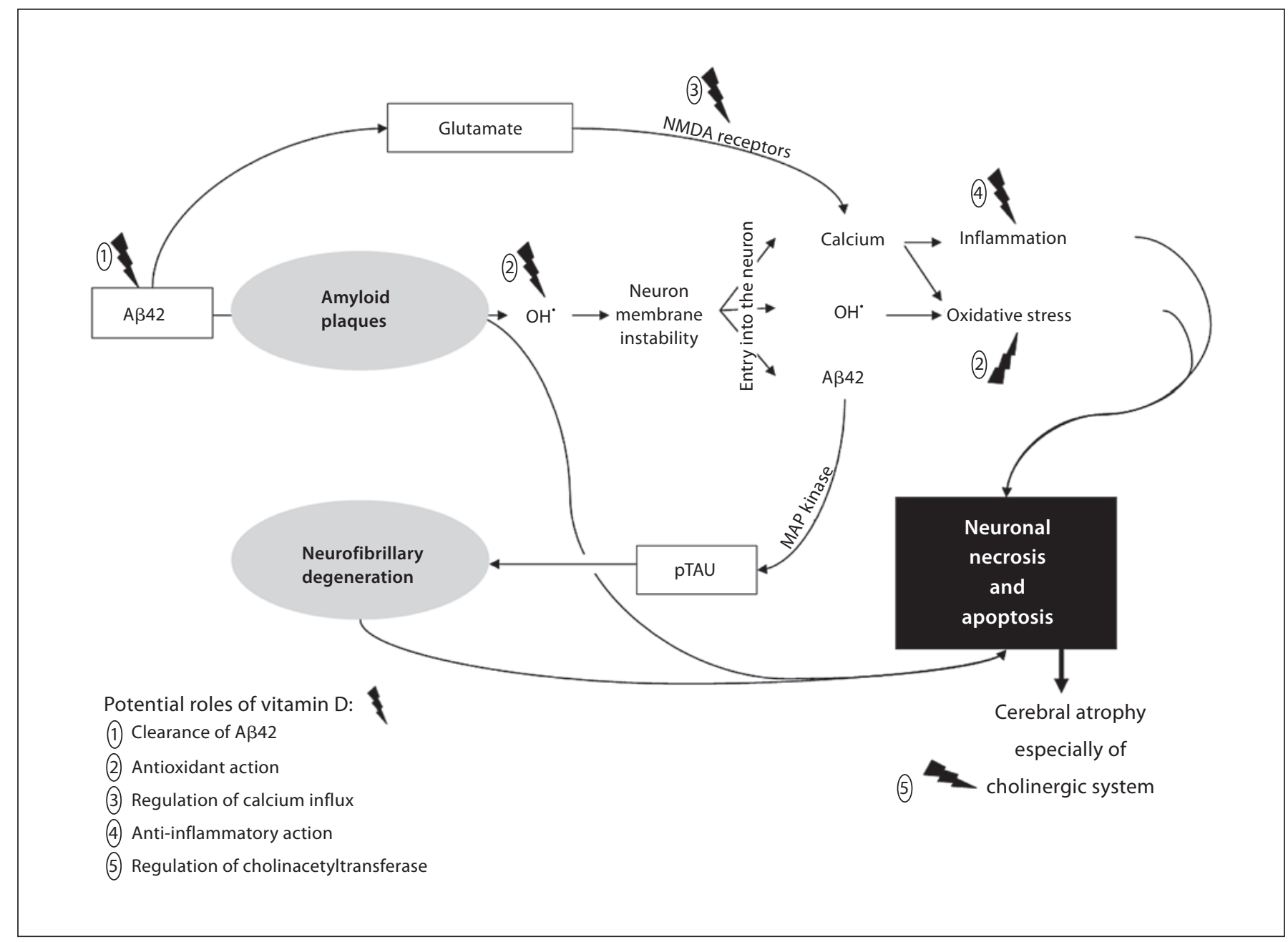

Fig. 1. Potential targets and neuroprotective mechanisms of vitamin $\mathrm{D}$ in $\mathrm{AD} . \mathrm{OH}^{-}=$Superoxide anion; NMDA = N-methyl D-aspartate; pTAU = phospho-tubule associated unit.

The clinical consequence of these degenerative processes is a decline in cognitive function that mainly leads to learning and memory difficulties.

\section{The Need for Multitarget Drugs in AD}

The drugs currently available (i.e., anticholinesterasics and memantine) are symptomatic and can only temporarily slow down $\mathrm{AD}$ symptoms $[25,26]$. Because of their symptomatic action, they are intended only for patients with mild to severe AD.

One of the main $\mathrm{AD}$ challenges over the coming decade lies in the finding of a curative drug that could modify the neurodegenerative process $[25,26]$. This strategy requires patients with no neurodegenerative lesions and thus at the earliest stages of $\mathrm{AD}$, which leads to a very limited selection of patients. For instance, the French National Centre for the Management of Trials on Healthcare Products (CeNGEPS), which involves more than ten university memory centers in France, included in 2009 only 260 patients in clinical trials for curative drugs, although there were potentially 24,000 subjects available in these centers [26]. In other words, curative drugs are addressing only $1.1 \%$ of $\mathrm{AD}$ patients followed in French university memory centers.

The question is then what can be offered to the other $\mathrm{AD}$ patients. A particularly attractive approach is the multitarget drugs approach, meaning that the treatment administered to the $\mathrm{AD}$ patient simultaneously targets several factors leading to neurodegeneration $[25,26]$. This last approach offers the opportunity to stabilize pa- 
tients at later stages of $\mathrm{AD}$, thus reducing chance inequalities between $\mathrm{AD}$ patients. This question is central since it could benefit a larger number of patients. Due to its numerous neurosteroid properties that regulate multiple brain targets (fig. 1) [1-3], we suggest that vitamin D could be a new multitarget therapy for AD.

\section{Neuroprotective Properties of Vitamin D}

Exactly how vitamin $\mathrm{D}$ and cognition are associated and if this association is causal has not been fully elucidated. On the one hand, low cognitive function could lead to low dietary intakes of vitamin D or a lack of sunlight exposure, which in turn lead to low vitamin D serum concentrations [4]. Most recent studies found yet a significant association of vitamin $\mathrm{D}$ with cognition even while adjusting for nutritional and physical status $[9,11$, $16,19,27-29]$. A scenario of reverse causation is thus plausible and should be considered: the association of hypovitaminosis $\mathrm{D}$ with $\mathrm{AD}$ could be a causal relationship explained by the neuroprotective properties of vitamin D. Vitamin D is a neurosteroid hormone the action of which is mediated by the vitamin $\mathrm{D}$ steroid receptors (VDR) present in neurons and glial cells of the CNS including hippocampus, hypothalamus, cortex and subcortex $[1,3]$. The binding of 1,25-dihydroxyvitamin $\mathrm{D}$ on VDR triggers protective mechanisms against degenerative processes implicated in AD (fig. 1) [3].

Firstly, VDR-dependent immunoregulatory effects permit an increase in the number of macrophages and polymorphonuclear leukocytes $[30,31]$. It has been proposed that vitamin $\mathrm{D}$ may reduce the accumulation of A $\beta 42$ peptide in stimulating the innate immune system, specifically the phagocytosis and clearance of amyloid $\beta$ peptide by macrophages [32].

Secondly, the neuroprotective effect of vitamin D also results from intraneuronal calcium homeostasis being maintained via the regulation of voltage-dependent calcium channels in the hippocampus, and via the synthesis of calcium-related cytoplasmic proteins such as parvalbumin or calcium-binding protein $[3,33]$.

Thirdly, vitamin D plays a part in the cerebral processes of detoxification by interacting with reactive oxygen and nitrogen species, especially in case of excessive entry of calcium into brain neurons [3]. Calcium not stored in the endoplasmic reticulum causes the activation of nitric oxide synthase and the synthesis of nitric oxide $\left(\mathrm{NO}^{\prime}\right)$ or the stimulation of phospholipase A2, the generation of superoxide anion $\left(\mathrm{O}_{2}^{-}\right)[23,24]$. $\mathrm{NO}^{\prime}$ can inter- act with $\mathrm{O}_{2}{ }^{-}$to form peroxynitrite $\left(\mathrm{OONO}^{-}\right)$. Oxy-reduction reactions resulting from free radicals induce dosedependent neuronal damage to deoxyribonucleic acid, membrane lipid by peroxidation, and enzyme inactivation. The consequences are cell contraction, relocation of organelles, condensation of chromatin, nuclear fragmentation, and production of apoptotic bodies containing fragments of cytoplasm and kernel, that defines neuronal apoptosis [23, 24]. The action of detoxification of vitamin $D$ was described on cultured rat mesencephalic cells, with an efficient protection against the superoxide ion, hydrogen peroxide, and intracellular free radicals generated by reactive oxygen species [34]. In addition, it has been demonstrated that vitamin D inhibits the synthesis of inducible nitric oxide synthase, an enzyme produced in CNS cells in response to stress, the high-dose action of which results in neuronal cell alteration [30]. The consequence of vitamin $\mathrm{D}$ administration is an increase in the number of survival neurons after exposure to cytotoxic stimuli.

Fourthly, besides neuronal protection, vitamin D may help in fighting brain atrophy via the control of neurotrophin levels and the number of mitoses [35]. In vitro, vitamin $\mathrm{D}$ increases the synthesis of neurotrophic agents such as nerve growth factor, glial cell line-derived neurotrophic factor, neurotrophin 3 , as well as the synthesis of low-affinity $\mathrm{p} 75_{\mathrm{NTR}}$ receptors $[1,35]$. It also accelerates neuronal growth in a dose-dependent way in rodent hippocampal cell cultures [35]. Vitamin D-related trophic induction seems to play a neuroprotective role in cerebral ischemia [36], as well as an antineurodegenerative role for dopaminergic cells in experimental animal models of Parkinson's disease [30]. The latter observation could be particularly interesting for secondary prevention and treatment of neurodegenerative diseases such as AD.

Fifthly, experimentation found that vitamin D supplementation in rats caused an increase in choline acetyltransferase activity (thus an increase in acetylcholine availability) in several specific brain areas, with potential applications during $\mathrm{AD}$ [37].

Finally, it has also been proposed that the avoidance of hyperparathyroidism in the case of normal vitamin D status may prevent the occurrence of cognitive and neuropsychiatric effects specifically induced by parathormone receptors in the brain $[8,38]$.

These multitarget mechanisms of protection could prevent at least part of the neuronal death and dysfunction, with subsequent benefits in terms of learning ability and memory. The question is whether correcting hypovitaminosis $\mathrm{D}$ among older adults can prevent neuronal death and hence cognitive decline. 


\section{What about Vitamin D Intake?}

In addition to these neurosteroid 'multitarget' effects, testing vitamin $\mathrm{D}$ therapy sounds interesting in that vitamin D could be associated with current antidementia drugs as part of a 'multi-drug' regimen. This is an important point when considering randomized controlled trials (RCT), since it seems almost impossible to get an RCT approved to examine the efficacy of vitamin $\mathrm{D}$ alone in $\mathrm{AD}$ patients after having removed standard therapies. In addition, supraphysiological doses of vitamin D are not likely necessary to obtain an effect, and it is probably sufficient to use consensual supplementation schemes with the sole purpose of raising the serum $25 \mathrm{OHD}$ concentrations above $30 \mathrm{ng} / \mathrm{ml}$ (i.e., $75 \mathrm{nmol} / \mathrm{l}$ ) [39]. Such therapeutic schemes do not reach toxic doses (i.e., higher than 10,000 IU per day) [39-41], which is of prime importance since hypervitaminosis D-induced hypercalcemia may increase AD risk [42]. Furthermore, conducting a placebo-controlled clinical trial in subjects with overt hypovitaminosis $\mathrm{D}$ for a 6-month period is acceptable because of the absence of expected accidents linked to vitamin $\mathrm{D}$ deficiency within this short period [43]. Despite all these facilitating arguments and the growing interest in vitamin D nonskeletal effects, no randomized placebo-controlled trial on the efficacy of vitamin $\mathrm{D}$ in $\mathrm{AD}$ patients has been conducted yet.

As a first approach, it seems useful to examine the impact of vitamin D intake on cognition (table 1). Vitamin $\mathrm{D}$ is a fat-soluble vitamin which exists in two forms: vitamin $D_{2}$ produced by irradiation of ergosterol by the action of ultraviolet (UV) radiation in the skin, and vitamin $\mathrm{D}_{3}$ provided directly by foods or produced by the action of UV from cholesterol after transformation to 7-dehydrocholesterol [4]. Three sources of vitamin D can therefore be distinguished: dietary intake, sun exposure, and drug supplements.

\section{Dietary Intake of Vitamin D and Cognition}

An association was recently highlighted between the weekly dietary intake of vitamin $\mathrm{D}$ and global cognitive performance $(\beta=0.002,95 \% \mathrm{CI}=0.001-0.003, \mathrm{p}<0.001$; table 1) [44]. The findings showed, among 5,596 community-dwelling older women (mean, 80.4 years), that inadequate vitamin $\mathrm{D}$ dietary intake was associated with cognitive impairment $(\mathrm{OR}=1.30,95 \% \mathrm{CI}=1.04-1.63, \mathrm{p}=$ 0.024 ) [44]. The latter result was obtained after exclusion of women having used vitamin D drug supplements during the past 18 months, and after adjustment for self-reported sun exposure at midday as well as age, body mass index, disability level, the number of comorbidities, hypertension, depression, use of psychoactive drugs, education level and season of assessment. Although this association could be explained in a more general way by a healthy lifestyle illustrated by a rich and varied diet and by regular physical activity, it was coherent with the previous literature. In particular, a pilot study published in 2007 found a correlation between the 3-day vitamin D dietary intake and cognitive impairment on the MMSE score $(\mathrm{r}=0.35, \mathrm{p}<0.01)$ among 69 community-dwellers aged 84 years on average ( $59.4 \%$ women; table 1 ) [45]. This work proposed a precise quantification of the dietary intake of vitamin $\mathrm{D}$, but was restricted to a limited size. Despite these methodological divergences, both studies found that high dietary intake of vitamin D was associated with high cognitive performance assessed with global composite cognitive scores $[44,45]$.

\section{Vitamin D Intake Related to Sun Exposure and Cognition}

Sun exposure of the skin is the second natural source of vitamin D [4]. To the best of our knowledge, no study has explored yet the effect of solar radiation on cognition. Only the study cited above assessed the link between sun exposure and cognitive status of older women [44]. In this study, the authors found an unadjusted association between sun exposure of the hands and face at least $15 \mathrm{~min}$ per day between 11 a.m. and 3 p.m., and global cognitive performance assessed with Pfeiffer's SPMSQ $(\beta=0.248$, $95 \% \mathrm{CI}=0.183-0.313, \mathrm{p}<0.001$; table 1 ) [41]. In addition, sun exposure protected against cognitive impairment $(\mathrm{OR}=0.641,95 \% \mathrm{CI}=0.542-0.758, \mathrm{p}<0.001)$ [44]. Nevertheless, both associations were not significant after adjustment for age, disability level, and other covariates $(\beta=0.037$ with $p=0.282$, and $\mathrm{OR}=0.944$ with $\mathrm{p}=0.552$, respectively), which was consistent with the observations that skin synthesis of vitamin D from UVB decreases with age [46] and that the effect of sun exposure is minor in the elderly compared to the other sources of vitamin D.

\section{Vitamin D Drug Supplements and Cognition}

The third source of vitamin D in the elderly is drug supplementation. To date, two studies have examined the effects of the use of vitamin D supplements on cognition (table 1) [47, 48]. The first one, by Przybelski et al. [47], failed to find a greater improvement of cognitive performance after the oral administration of 50,000 IU vitamin 


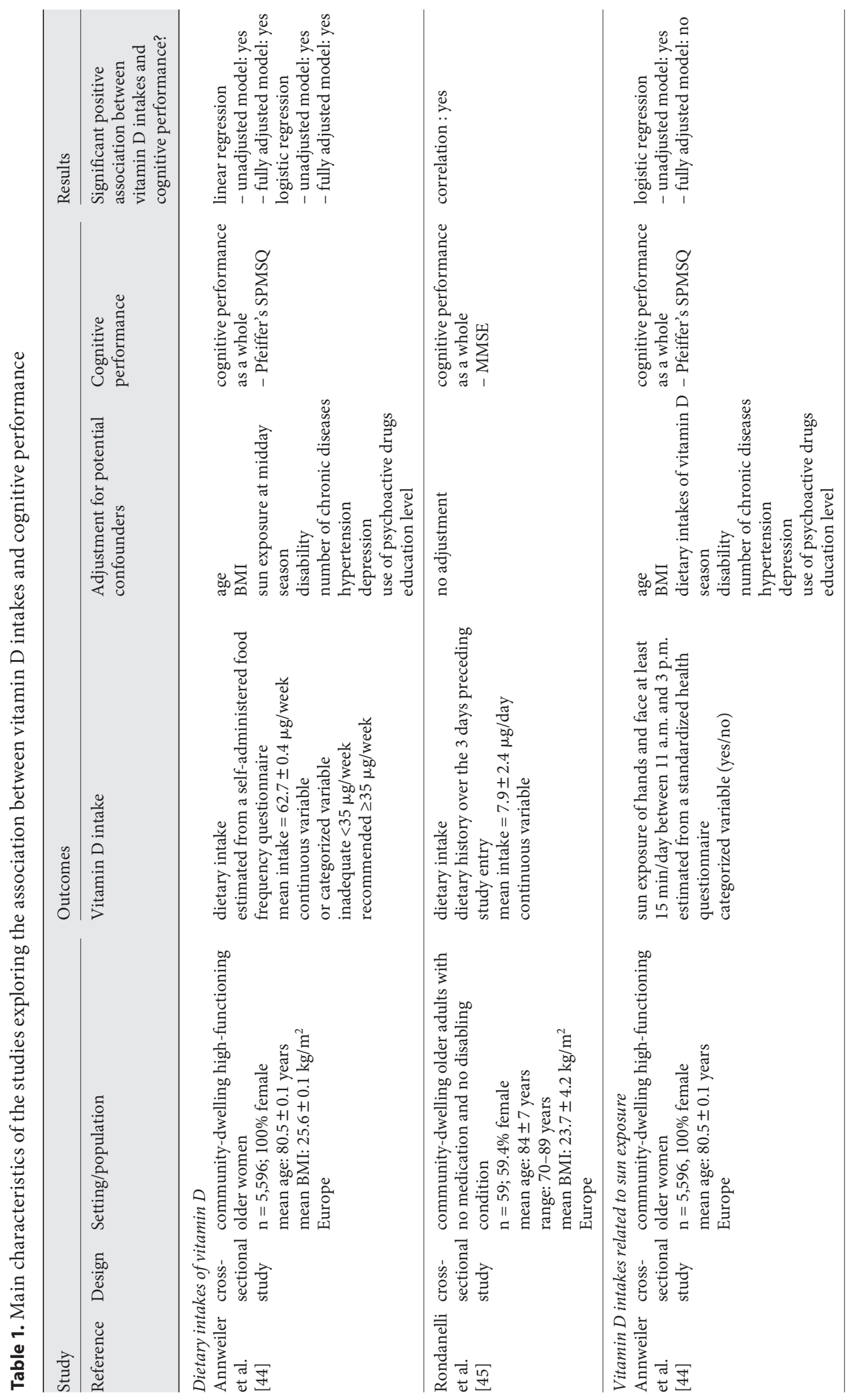




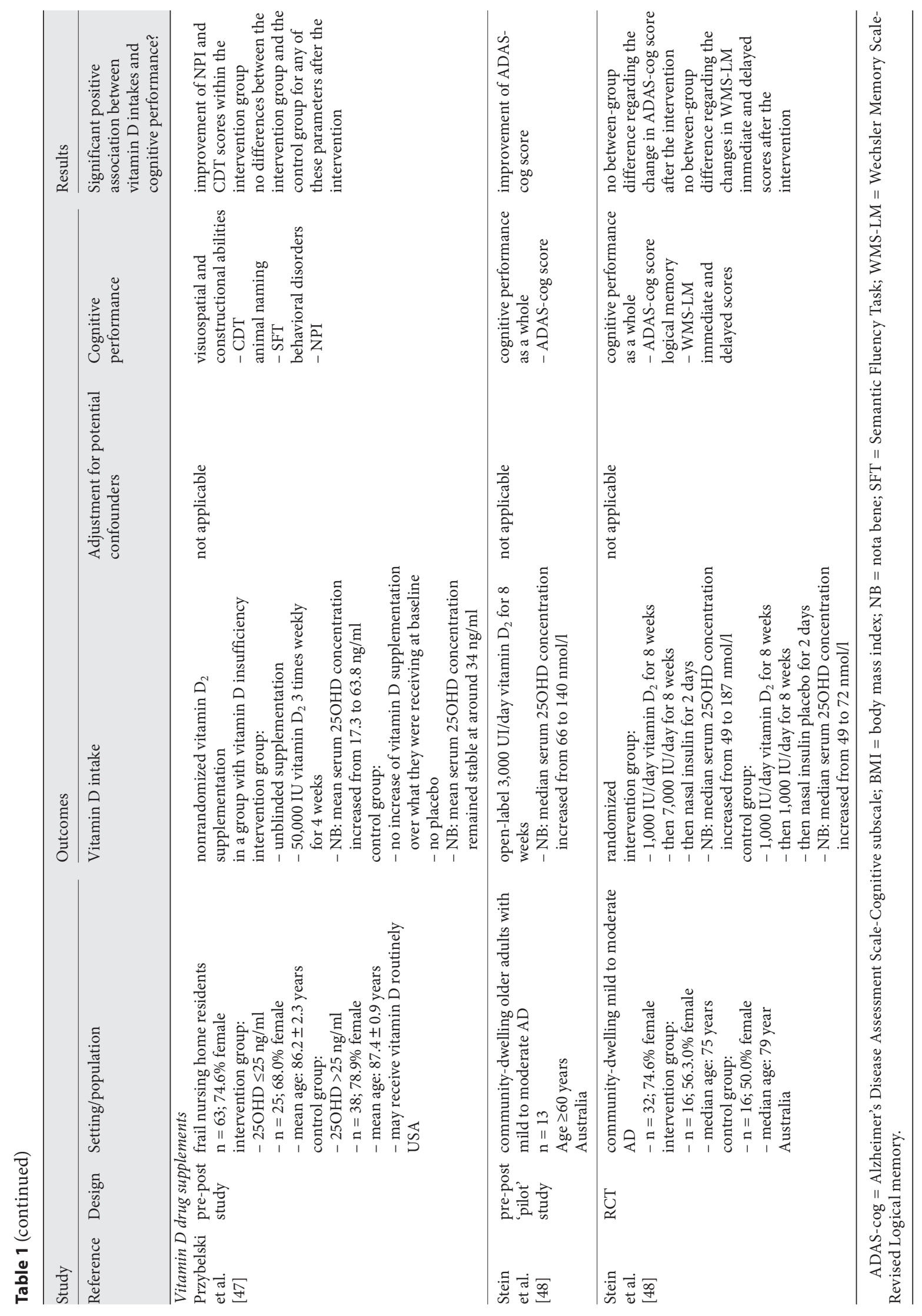


$\mathrm{D}_{2} 3$ times a week for 4 weeks among 25 older residents with hypovitaminosis D (mean age, 86.2 years; 68\% women), compared to 38 residents with a normal vitamin $\mathrm{D}$ status who did not receive any vitamin $\mathrm{D}$ supplements (mean age, 87.4 years; $78.9 \%$ women; mean baseline 25OHD, $34.8 \pm 1.8 \mathrm{ng} / \mathrm{ml}$; table 1) [47]. In particular, no significant between-group difference was observed after 4 weeks of treatment with regards to the performance on Semantic Fluency Task, Clock Drawing Test (CDT) and Neuropsychiatric Inventory (NPI). Nevertheless, this pre-post study also showed that the increase in serum 25OHD concentrations among the treatment group (from 17.3 to $63.8 \mathrm{ng} / \mathrm{ml}, \mathrm{p}<0.0001$ ) was coupled with an improved NPI score (from $7.3 \pm 2.0$ before vitamin D supplementation to $5.5 \pm 1.9$ after treatment; lower scores indicate reduced intensity and/or frequency of neuropsychiatric symptoms) and an improved CDT score $(5.7 \pm 0.5$ after treatment vs. $5.1 \pm 0.5$ before treatment; table 1) [47]. The scores were also improved among the group with a normal vitamin D status (NPI score changing from $7.4 \pm 1.6$ to $6.4 \pm 1.6$; and CDT score from 4.6 \pm 0.6 to $5.7 \pm 0.5$ ), but the authors did not provide the degree of significance of these differences. Anyway, the improvement of the neuropsychiatric symptoms among participants with no hypovitaminosis D was interestingly concordant with previous experiments in rodents proposing that hypovitaminosis $\mathrm{D}$ could be involved in the occurrence of behavioral disorders. In particular, the model of resistance to vitamin $\mathrm{D}$ (similar to avitaminosis D) provided by the transgenic VDR knockout (VDR-KO) mouse showed a deleterious impact on behavior, primarily marked by excessive stress, motor disorders [49], aberrant maternal behaviors and aggressiveness [50]. Since behavioral disorders are common in the course of $\mathrm{AD}$ and are often a challenging issue due to the use of chemical restraints and the need for institutionalization [51], this finding may be of prime importance and should be investigated in more depth.

The second study on this topic, by Stein et al. [48], had two phases. First, the authors conducted a feasibility pilot study, consisting in a pre-post study based on the open supplementation of $3,000 \mathrm{IU}$ vitamin $\mathrm{D}_{2}$ per day for 8 weeks in 13 older patients with mild to moderate AD (table 1). In line with the study by Przybelski et al. [47], the increase in serum 25OHD concentration from 66 to 140 $\mathrm{nmol} / \mathrm{l}$ was accompanied by a 6-point improvement of the ADAS-cog score (range: 4.5-8.5, p < 0.001) [48]. The second phase of the study by Stein et al. [48] consisted in a randomized control trial designed to correct hypovitaminosis $\mathrm{D}$ among $32 \mathrm{AD}$ participants with open-label
1,000 IU vitamin $D_{2}$ per day for 8 weeks, and then to examine the cognitive effectiveness of supraphysiological doses of vitamin $\mathrm{D}_{2}$ in $16 \mathrm{AD}$ patients (i.e., 7,000 IU/day) compared to 16 other AD patients receiving physiological doses of vitamin $\mathrm{D}_{2}$ (i.e., 1,000 IU/day; table 1). The authors failed to find a significant between-group difference regarding the change in ADAS-cog and WMS-LM scores on the whole cohort (table 1), highlighting the fact that supraphysiological doses of vitamin D were not more efficient in improving cognitive abilities than physiological ones [48].

These two studies, whether by Przybelski et al. [47] or by Stein et al. [48], had yet a number of methodological problems that limited their conclusions. For instance, they were both limited by the use of vitamin $\mathrm{D}_{2}$ supplements which are generally less efficient than vitamin $\mathrm{D}_{3}$ for repletion [52], and by the short duration of the followup that did not exceed 16 weeks, while the effects of vitamin D can be observed after a longer period [43]. Additionally, none of these studies assessed executive functions or episodic memory as outcome measures, although serum $25 \mathrm{OHD}$ concentrations are likely associated with these domain-specific cognitive functions, as described above. It should also be mentioned that no stratification was made on the stages of AD by Stein et al. [48], although the preventive effects of vitamin D may be more evident in the early stages of the dementia process than in later stages. This should have justified a separate analysis for each AD stage; and most importantly, both studies compared participants who received vitamin D supplements to participants who had already a normal vitamin $\mathrm{D}$ status, which did not allow drawing conclusions about the cognitive effectiveness of the correction of hypovitaminosis D.

In conclusion, it appears that cognitive decline in $\mathrm{AD}$ and hypovitaminosis D have a partially common pathophysiological pathway based on impaired protection against oxidative stress, accumulation of $\beta$ amyloid protein and calcium excitotoxicity. On the contrary, vitamin $\mathrm{D}$ experimentally protects neurons against degenerative mechanisms implicated in AD and could be a new multitarget therapy for AD both easily applicable and inexpensive. The previously described cross-sectional associations between vitamin $\mathrm{D}$ intakes - whether from diet, sun exposure or drug supplements - and cognition strengthened this hypothesis, but prevented determining whether cognitive decline precipitated low intakes of vitamin $\mathrm{D}$ due to disability, or whether low intakes of vitamin $\mathrm{D}$ had a role in precipitating cognitive decline. In this regard, pre-post studies suggest an improvement of cog- 
nition concomitant with the increase in 25OHD concentrations, even if supraphysiological doses of vitamin D seemed not better than physiological doses at improving cognition in the only RCT conducted to date. This observation is consistent with the recent conclusions of the Institute of Medicine highlighting that available evidence in favor of the nonskeletal effects of vitamin D are still limited [53]. At this stage, only RCTs testing the effectiveness of vitamin D supplements versus placebo on the evolution of cognition as a whole, and specifically of episodic memory and executive functions, can further determine the impact of vitamin $\mathrm{D}$ repletion in $\mathrm{AD}$ with a higher level of evidence.

\section{Disclosure Statement}

Sponsor's role: none.

Conflicts of interest: Dr. Annweiler serves as an unpaid consultant for Ipsen Pharma Co. He has no relevant financial interest in this article.

Prof. Beauchet: serves as an unpaid consultant for Ipsen Pharma Co., and serves as an editor for Gériatrie, Psychologie et Neuropsychiatrie du Vieillissement. He has no relevant financial interest in this article.

\section{References}

$\checkmark 1$ Kalueff A-V, Tuohimaa P: Neurosteroid hormone vitamin $\mathrm{D}$ and its utility in clinical nutrition. Curr Opin Clin Nutr Metab Care 2007:10:12-19.

-2 Buell J-S, Dawson-Hughes B: Vitamin D and neurocognitive dysfunction: preventing 'D'ecline? Mol Aspects Med 2008;29:415422.

- 3 Annweiler C, Schott A-M, Berrut G, et al: Vitamin $\mathrm{D}$ and ageing: neurological issues. Neuropsychobiology 2010;62:139-150.

4 Holick M-F: Vitamin D deficiency. N Engl J Med 2007;357:266-281.

5 Miller J-W: Vitamin D and cognitive function in older adults: are we concerned about vitamin D-mentia? Neurology 2010;74:1315.

6 McCann J-C, Ames B-N: Is there convincing biological or behavioral evidence linking vitamin D deficiency to brain dysfunction? FASEB J 2008;22:982-1001.

7 Grant WB. Does vitamin D reduce the risk of dementia? J Alzheimers Dis 2009;17:151159.

-8 Annweiler C, Allali G, Allain P, et al: Vitamin $\mathrm{D}$ and cognitive performance in adults: a systematic review. Eur J Neurol 2009;16: 1083-1089.

-9 Annweiler C, Schott A-M, Allali G, et al: Association of vitamin $\mathrm{D}$ deficiency with cognitive impairment in older women: crosssectional study. Neurology 2010;74:27-32.

10 Slinin Y, Paudel M-L, Taylor B-C, et al: 25 -Hydroxyvitamin D levels and cognitive performance and decline in elderly men. Neurology 2010;74:33-41.

-11 Llewellyn D-J, Lang I-A, Langa K-M, et al: Vitamin D and risk of cognitive decline in elderly persons. Arch Intern Med 2010;170: 1135-1141.
12 Annweiler C, Fantino B, Le Gall D, et al: Severe vitamin $\mathrm{D}$ deficiency is associated with advanced-stage dementia amongst geriatric inpatients. J Am Geriatr Soc 2011;59:169171.

13 Sato Y, Asoh T, Oizumi K: High prevalence of vitamin $\mathrm{D}$ deficiency and reduced bone mass in elderly women with Alzheimer's disease. Bone 1998;23:555-557.

14 Evatt M-L, Delong M-R, Khazai N, et al: Prevalence of vitamin D insufficiency in patients with Parkinson disease and Alzheimer disease. Arch Neurol 2008;65:1348-1352.

15 Buell J-S, Dawson-Hughes B, Scott T-M, et al: 25-Hydroxyvitamin D, dementia, and cerebrovascular pathology in elders receiving home services. Neurology 2010;74:1826.

16 Llewellyn D-J, Lang I-A, Langa K-M, et al: Vitamin D and cognitive impairment in the elderly U.S. population. J Gerontol A Biol Sci Med Sci 2011;66:59-65.

17 Colette F, Van der Linden M, Salmon E: Executive dysfunction in Alzheimer's disease. Cortex 1999;35:57-72.

18 Miyake A, Friedman N-P, Emerson M-J, et al: The unity and diversity of executive functions and their contributions to complex 'frontal lobe' tasks: a latent variable analysis. Cognit Psychol 2000;41:49-100.

19 Buell J-S, Scott T-M, Dawson-Hughes B, et al: Vitamin D is associated with cognitive function in elders receiving home health services. J Gerontol A Biol Sci Med Sci 2009;64: 888-895.

20 Querfurth H-W, LaFerla F-M: Alzheimer's disease. N Engl J Med 2010;362:329-344

21 Sokolow S, Luu S-H, Vinters H-V, et al: Glutamatergic (VGLUT1) synapses are not lost in Alzheimer's disease cerebral cortex, but preferentially accumulate amyloid-beta and p-tau pathology. Alzheimers Dement 2010; 6:S243.
22 Gouras G-K, Tampellini D, Takahashi R-H, et al: Intraneuronal beta-amyloid accumulation and synapse pathology in Alzheimer's disease. Acta Neuropathol 2010;119:523541.

23 Ankarcrona M, Dypbukt J-M, Bonfoco E, et al: Glutamate-induced neuronal death: a succession of necrosis or apoptosis depending on mitochondrial function. Neuron 1995; 15:961-973.

24 Bonfoco E, Krainc D, Ankarcrona M, et al: Apoptosis and necrosis: two distinct events induced, respectively, by mild and intense insults with $\mathrm{N}$-methyl-D-aspartate or nitric oxide/superoxide in cortical cell cultures. Proc Natl Acad Sci USA 1995;92:7162-7166.

25 Aisen P-S: Pre-dementia Alzheimer's trials: overview. J Nutr Health Aging 2010;14:294.

26 Vellas B, Aisen P-S: Early Alzheimer's trials: new developments. J Nutr Health Aging 2010;14:293.

-27 Lee D-M, Tajar A, Ulubaev A, et al: Association between 25-hydroxyvitamin D levels and cognitive performance in middle-aged and older European men. J Neurol Neurosurg Psychiatry 2009;80:722-729.

28 Wilkins C-H, Birge S-J, Sheline Y-I, et al: Vitamin D deficiency is associated with worse cognitive performance and lower bone density in older African Americans. J Natl Med Assoc 2009; 101:349-354

29 Seamans K-M, Hill T-R, Scully L, et al: Vitamin D status and measures of cognitive function in healthy older European adults. Eur J Clin Nutr 2010;64:1172-1178.

-30 Garcion E, Wion-Barbot N, Montero-Menei $\mathrm{C}-\mathrm{N}$, et al: New clues about vitamin D functions in the nervous system. Trends Endocrinol Metab 2002;13:100-105 
-31 Moore M-E, Piazza A, McCartney Y, Lynch MA: Evidence that vitamin D3 reverses agerelated inflammatory changes in the rat hippocampus. Biochem Soc Trans 2005;33:573577.

-32 Masoumi A, Goldenson B, Ghirmai S, et al: 1alpha,25-dihydroxyvitamin D3 interacts with curcuminoids to stimulate amyloid-beta clearance by macrophages of Alzheimer's disease patients. J Alzheimers Dis 2009;17: 703-717.

-33 De Viragh P-A, Haglid K-G, Celio M-R: Parvalbumin increases in the caudate putamen of rats with vitamin D hypervitaminosis. Proc Natl Acad Sci USA 1989;86:38873890.

-34 Ibi M, Sawada H, Nakanishi M, et al: Protective effects of 1 alpha, 25-(OH)(2)D(3) against the neurotoxicity of glutamate and reactive oxygen species in mesencephalic culture. Neuropharmacology 2001;40:761-771.

- 35 Brown J, Bianco J-I, McGrath J-J, et al: 1,25-Dihydroxyvitamin D-3 induces nerve growth factor, promotes neurite outgrowth and inhibits mitosis in embryonic rat hippocampal neurons. Neurosci Lett 2003;343: 139-143.

-36 Wang Y, Chiang Y-H, Su T-P, et al: Vitamin D3 attenuates cortical infarction induced by middle cerebral arterial ligation in rats. Neuropharmacology 2000;39:873-880.

-37 Sonnenberg J, Luine V-N, Krey L-C, et al: 1,25-Dihydroxyvitamin D3 treatment results in increased choline acetyltransferase activity in specific brain nuclei. Endocrinology 1986;118:1433-1439.
38 Annweiler C, Le Gall D, Fantino B, et al: 25-Hydroxyvitamin D, dementia, and cerebrovascular pathology in elders receiving home services. Neurology 2010;75:95.

-39 Souberbielle J-C, Prié D, Courbebaisse M, et al: Update on vitamin D and evaluation of vitamin D status. Ann Endocrinol (Paris) 2008;69:501-510.

40 Vieth R: Vitamin D supplementation, 25-hydroxyvitamin D concentrations, and safety. Am J Clin Nutr 1999;69:842-856.

41 Hathcock J-N, Shao A, Vieth R, et al: Risk assessment for vitamin D. Am J Clin Nutr 2007;85:6-18.

42 van Vliet P, Oleksik A-M, Mooijaart S-P, et al: APOE genotype modulates the effect of serum calcium levels on cognitive function in old age. Neurology 2009;72:821-828.

43 Annweiler C, Montero-Odasso M, Schott $\mathrm{AM}$, et al: Fall prevention and vitamin $\mathrm{D}$ in the elderly: an overview of the key role of the non-bone effects. J Neuroeng Rehabil 2010;7: 50

44 Annweiler C, Schott A-M, Rolland Y, et al: Dietary intake of vitamin $\mathrm{D}$ and cognition in older women: a large population-based study. Neurology 2010;75:1810-1816.

45 Rondanelli M, Trotti R, Opizzi A, et al: Relationship among nutritional status, pro/antioxidant balance and cognitive performance in a group of free-living healthy elderly. Minerva Med 2007;98:639-645.
46 MacLaughlin J, Holick M-F: Aging decreases the capacity of human skin to produce vitamin D3. J Clin Invest 1985;76:1536-1538.

-47 Przybelski R, Agrawal S, Krueger D, et al: Rapid correction of low vitamin D status in nursing home residents. Osteoporos Int 2008;19:1621-1628.

-48 Stein M-S, Scherer S-C, Ladd K-S, et al: A randomized controlled trial of high-dose vitamin D2 followed by intranasal insulin in Alzheimer's disease. J Alzheimers Dis 2011; 26:477-484.

49 Burne T-H, Johnston A-N, McGrath J-J, et al: Swimming behaviour and post-swimming activity in vitamin $\mathrm{D}$ receptor knockout mice. Brain Res Bull 2006;69:74-78.

50 Kalueff A-V, Keisala T, Minasyan A, et al: Behavioural anomalies in mice evoked by 'Tokyo' disruption of the vitamin D receptor gene. Neurosci Res 2006;54:254-260.

51 Lai C-K, Yeung J-H, Mok V, et al: Special care units for dementia individuals with behavioural problems. Cochrane Database Syst Rev 2009;4:CD006470.

52 Romagnoli E, Mascia M-L, Cipriani C, et al: Short and long-term variations in serum calciotropic hormones after a single very large dose of ergocalciferol (vitamin D2) or cholecalciferol (vitamin D3) in the elderly. J Clin Endocrinol Metab 2008;93:3015-3020.

53 Ross A-C, Manson J-E, Abrams S-A, et al: The 2011 report on dietary reference intakes for calcium and vitamin D from the Institute of Medicine: what clinicians need to know. J Clin Endocrinol Metab 2011;96:53-58. 